\title{
ROLE OF HYDROPHILIC SURFACTANTS IN THE EMULSIFICATION MECHANISTICS OF TYPE III SELF-MICRO-EMULSIFYING DRUG DELIVERY SYSTEMS (SMEDDS)
}

\author{
NASER M. Y. HASAN* \\ School of Pharmacy, Applied Science Private University, Jordan \\ Email: n_hassan@asu.edu.jo \\ Received: 13 Sep 2018, Revised and Accepted: 05 Mar 2019
}

\begin{abstract}
Objective: Evaluation of the self-emulsifying behaviour of type III lipid systems comprising mixed medium chain glycerides (Miglyol 812-Imwitor 988) and wide range of hydrophilic surfactants in an attempt to identify self-emulsifying microemulsion formulations, prevaricate the crystallization tendency of Cremophor RH40 in the pre-microemulsion concentrate, to shed some light on the mechanistic behavior of these systems after aqueous dispersion
\end{abstract}

Methods: Non-ionic surfactants with HLB in the range 14 to 16.5 are investigated amongst these are; Cremophor RH40, Cremophor EL, Crillet 4 (polysorbate 80), Crillet 1 (polysorbate 20) and Tagat 02. Optimum oil blends of Miglyol 812-Imwitor 988 and various non-ionic surfactant systems were verified using self-emulsification performance studies, oil droplet diameter measurements and dynamic equilibrium phase studies.

Results: Oil blends of Miglyol 812 as an oil and Imwitor 988 as a cosurfactant were optimized for microemulsion systems at ratios of 1:1 in the case of Cremophor RH40 or EL, and at 2:3 in the case of Crillet 4 or Tagat 02. In order to obtain small droplet size and fast dispersion rate for type III lipid systems, hydrophilic surfactants with HLB values between 13 and 15 were found to be the optimum.

Conclusion: Spontaneous micro-emulsification in type III lipid system was attributed to the "diffusion and stranding" theory. Yet, the formation of liquid crystalline phases as intermediate phases during dilution of the oil formulation with water appears to be quintessential for the mechanistics of emulsification regardless type of lipid class system.

Keywords: SEDDS, SMEDDS, Lipid formulations, Medium chain mono-and glycerides, Poorly water-soluble compounds

(C) 2019 The Authors. Published by Innovare Academic Sciences Pvt Ltd. This is an open-access article under the CC BY license (http://creativecommons.org/licenses/by/4.0/) DOI: http://dx.doi.org/10.22159/ijap.2019v11i3.29732

\section{INTRODUCTION}

Self-emulsifying drug delivery systems (SEDDS) or self-microemulsifying drug delivery system (SMEDDS) are isotropic mixtures of oils, non-ionic surfactants and co-surfactants which are used for improving lipophilic drug dissolution and absorption. These systems upon mild agitation in aqueous media form fine oil-in-water emulsions of droplet size of $<5 \mu \mathrm{m}$ in the case of SEDDS [1] or droplets with diameters between 5 and $140 \mathrm{~nm}$ in the case of SMEDDS [2]. It is proposed that enhancement in the water solubilisation region $\left(\mathrm{L}_{2}\right)$ and the formation of interfacial liquid crystal on dilution with water are important to the mechanistic processes [3-4]. Furthermore, it is important in order to maximize the rate of absorption and thus bioavailability of oily formulations; one must maintain the drug in solution and avoid crystallization of the drug on dilution in the lumen of the gut $[3,5,6]$. Self-emulsifying technology for oral delivery use has recently witnessed the introduction of many self-emulsifying microemulsion formulations [7] including; $\mathrm{Neoral}^{\circledR}$, originally marketed as 'Sandimmune ${ }^{\mathrm{TM}}$ ' (Cyclosporin A, calcineurin inhibitor; new drug application year NDA 1999), Norvir ${ }^{\circledR}$ (Ritonavir, protease inhibitor; NDA 1996), Targretin ${ }^{\circledR}$ (Bexarotene, protease inhibitor; NDA 1999), Rapamune ${ }^{\circledR}$ (Sirolimus, mTOR kinase inhibitor: NDA 1999), Avodart ${ }^{\circledR}$ (Dutasteride, 5 alpha-reductase inhibitor; NDA 2001, Aptivus ${ }^{\circledR}$ (Tipranavir, protease inhibitor; NDA 2005), Amitiza ${ }^{\circledR}$ (Lubiprostone, chloride channel activator; NDA 2006), Xtandi ${ }^{\circledR}$ (Enzalutamide, androgen receptor inhibitor; NDA 2012) and Rayaldee ${ }^{\circledR}$ (Calcifediol, vitamin D analog; NDA 2016). However, the design for effective selfmicro-emulsifying drug delivery systems (SMEDDS) needs through an understanding of the various key elements which influence emulsification and how these factors interplay to affect absorption [3-4]. Pouton [8-9] has suggested a classification system for lipidic formulations based on their dispersions characteristics, digestibility and the physicochemical characteristics of the formulation components; principally the HLB of the surfactants and \% glycerides content. Under this system, simple surfactant-free lipid solution formulations are classified as type I. Type II formulations are often referred to as SEDDS which comprise water-insoluble components; blends of glycerides and non-ionic surfactants with HLBs less than 12 such as; polysorbate 85 (Tween 85 ) or polyoxyethylene 25glyceryl trioleate (Tagat TO). Type III systems contain blends of glycerides (oils), hydrophilic surfactants with HLB>12 such as; Cremophor RH40 $[10,11]$, Cremophor EL $[12,13]$, Tween $80[14$, 15], Tween 20 [14] or Tagat 02 [16] and/or hydrophilic co-solvents such as, ethanol, propylene glycol or polyethylene glycol. Type III formulations which include water-soluble components are referred to as self-micro-emulsifying systems (SMEDDS) as they can lead to the production of a microemulsion on dispersion in GI tract (particle size $\approx 50 \mathrm{~nm}$ ). Type III formulations can be subdivided into type IIIA and type IIIB according to the degree of hydrophilicity of these formulations. Type IIIA formulation contains approximately 50-60\% triglycerides or mixed glyceride content, whereas type IIIB has less than 20\%. Type IV formulations do not contain natural lipids and represent the most hydrophilic formulations. The HIV protease inhibitor amprenavir (Agenerase $($ ) which contains TPGS as a surfactant and PEG 400 and propylene glycol as co-solvents [17] is an example of Type IV formulations which do not contain natural lipids and thus represent the most hydrophilic formulations. The optimization of cyclosporin as Neoral ${ }^{\circledR}$ is the archetypal example of Type IIIB according to the classification system proposed by Pouton [8, 9]. The Neoral ${ }^{\circledR}$ formulation uses approximately $20 \%$ co-solvent, $30 \%$ oil and $40 \%$ hydrophilic nonionic surfactant (Cremophor RH40) and $10 \%$ drug. Apparently, the use of Cremophor RH40 (polyoxyethylene(40)-hydrogenated caster oil) has significantly contributed to the success of this formulation as a microemulsion delivery system. Yet the role of this surfactant in the emulsification process from mechanistic and phase behaviour perspective has not been reported.

In this study blends of Miglyol 812, Imwitor 988 and various hydrophilic nonionic surfactants were optimized to produce microemulsion systems. The effect of varying weight ratio of each component on the emulsification performance for various microemulsion systems as determined by size measurement was investigated. Furthermore, the equilibrium phase behaviour study was also conducted to establish the mechanism by which hydrophilic surfactants influence emulsification process. 


\section{MATERIALS AND METHODS}

\section{Materials}

Miglyol 812 (medium chain triglyceride) and Imwitor $988\left(\mathrm{C}_{8} / \mathrm{C}_{10}\right.$ mono/diglycerides) were supplied by Condea Chemie GmbH. Tagat TO (PEG-(25)-glyceryl trioleate) and Tagat $\mathrm{O}_{2}$ (polyoxyethylene(20)-glyceryl monooleate), supplied by Goldschmidt AG, Germany. Crillet 4 (Polyoxyethylene-(20)-sorbitan monooleate), also known as tween 80 or polysorbate 80 and crillet 1 (Polyoxyethylene-(20)sorbitan monolaurate), also known as Tween 20 or polysorbate 20 were supplied as gifts from Croda UK. Cremophor RH 40 (polyoxyethylene-(40)-hydrogenated caster oil) and cremophor EL (polyoxyethylene-(35)-caster oil) were obtained from BASF Corporation. All water used was Mili Q water.

\section{Methods}

\section{Miscibility ternary phase diagrams}

Regions of mutual solubility of various lipid formulations with a wide range of surfactants that represent different HLB values were determined using ternary phase diagrams. Miscibility diagrams of miglyol 812, imwitor 988 and various surfactants; tagat T0, tagat 02, crillet 4, crillet 1, cremophor RH 40 and cremophor EL were constructed. Each of the axes on the diagram represents the percentage contributes to the formulation by each of the three components (miglyol 812, imwitor 988 and a surfactant). Formulations of five grams which represent various percentages of Miglyol 812, Imwitor 988 and a surfactant on the ternary phase diagrams, were weighed in $20 \mathrm{~g}$ screw-capped vials (tops were rapped with cling film before caps were screwed on). Mixtures were placed in a water bath at $50{ }^{\circ} \mathrm{C}$ for $2 \mathrm{~min}$ before the three components were thoroughly vortexed. Mixtures were then kept for 24-48 $\mathrm{h}$ in an oven set up at $25^{\circ} \mathrm{C}$ before visual assessment. In the case of Miglyol 812/Imwitor 988-Cremophor RH40 system, mixtures were kept for $24-48 \mathrm{~h}$ in an oven set up at various storage temperatures of $15^{\circ} \mathrm{C}, 25$ ${ }^{\circ} \mathrm{C}$ or $45^{\circ} \mathrm{C}$. Mixtures which formed a continuous single-phase were classified as miscible formulations. Samples that displayed two or more phases were described as immiscible systems.

\section{Self-emulsification}

Mixtures of oil and surfactant were produced by accurately weighing ingredients into screw-capped glass vials with tight closures followed by votrexing. Different proportions (w/w) of Miglyol 812/Imwitor 988 $(10: 0,9: 1,8: 2,7: 3,6: 4,5: 5,3: 7,1: 9$ and 0:10) containing between 5 and $60 \% \mathrm{w} / \mathrm{w}$ surfactant were weighed first in the glass vials, tops were then rapped with cling film before caps were screwed on. The glass vials were held at $50{ }^{\circ} \mathrm{C}$ in a thermostated water bath held for 2 minute before lipid mixtures were thoroughly vortexed. Lipid formulations were then left to equilibrate overnight in an oven set up at $25^{\circ} \mathrm{C}$. Emulsions were prepared under conditions of gentle agitation at a controlled temperature of $37^{\circ} \mathrm{C}$. Self-emulsifiable mixtures $(1 \mathrm{gm})$ were introduced into $100 \mathrm{ml}$ of Mili Q water in a $500-\mathrm{ml}$ glass beaker held at $37^{\circ} \mathrm{C}$ in a thermostated water bath. All materials were preequilibrated to the appropriate temperature. Emulsification under agitation conditions considered to be a reasonable simulation of the in vivo situation was carried out. Agitation was provided by gentle shaking on a mechanical shaker at 100 oscillations per min for $15 \mathrm{~min}$. Systems which appeared to emulsify efficiently were studied further by particle size analysis.

\section{Analysis of mean emulsion droplet diameter (MEDD)}

For emulsions with droplet distributions above $1 \mu \mathrm{m}$, low angle laser light diffraction (Malvern Mastersizer X) with small volume cell using $45 \mathrm{~mm}$ lens was used. On the other hand, Quasi-elastic light scattering (QELS, Malvern model LO-C photon correlation spectrometer) was used to analyze samples of submicron dispersions. For both techniques, experiments were performed in triplicate. Size distributions of the resultant emulsions were obtained and expressed as mean values of all data \pm standard error.

\section{Equilbrium phase studies}

Phase behaviour studies were conducted by static composition method described by Hasan et al. [4]: Mixtures representing whole ternary phase diagram at $5 \% \mathrm{w} / \mathrm{w}$ intervals containing blends of oil, surfactant and water of total weight of 5 gm were weighed up in screw-capped glass vials. In order to make phase boundaries, additional compositions were made at $2.5 \% \mathrm{w} / \mathrm{w}$ intervals whenever is required. Oil compositions were heated to $70{ }^{\circ} \mathrm{C}$ in a thermostatically controlled water bath for $15 \mathrm{~min}$ and vortexed until homogeneity was achieved. Oil blends were then allowed to equilibrate at $25^{\circ} \mathrm{C}$ for $24 \mathrm{~h}$ for phase identification using Alan crossed polarized viewer.

\section{RESULTS AND DISCUSSION}

\section{Miscibility of ternary oil systems}

Fig. $1(\mathrm{a}, \mathrm{b}$, and $\mathrm{c})$ depicts ternary phase diagrams displaying the miscibility of Miglyol 812/Imwitor 988-cremophor RH40 system at various storage temperatures $15^{\circ} \mathrm{C}, 25^{\circ} \mathrm{C}$ and $45^{\circ} \mathrm{C}$, respectively. As fig. 1 shows Miglyol 812 and Imwitor 988 are completely miscible at all temperatures used. Furthermore, it is evident that Cremophor RH40 in this system at temperatures $15{ }^{\circ} \mathrm{C}$ or $25^{\circ} \mathrm{C}$ (fig. $1 \mathrm{a}, \mathrm{b}$ ) is partially miscible in Imwitor 988 or Miglyol 812. Yet, it is important to note that blends of Cremophor RH40 and Imwitor 988 might be completely miscible and what we see from the area of immiscibility close to the Imwitor 988 line is due to the solidification of Cremophor RH40 at temperatures below its melting point (mp) 40 ${ }^{\circ} \mathrm{C}$. This is substantiated, however, as the area of immiscibility between Cremophor RH40 and Imwitor 988 has disappeared when oil blends were heated at $45^{\circ} \mathrm{C}$ (fig. 1c) which is above the melting point of Cremophor RH40 or, when waxy Cremophor $\mathrm{RH} 40$ is replaced with its liquid unsaturated form Cremophor EL, see fig. 2. At $45^{\circ} \mathrm{C}$, however, only blends of cremophor RH40 and miglyol 812 show partial miscibility as they form one bimodal curve. Generally, increasing the temperature leads to a reduction in the areas of immiscibility and thus miscibility is promoted. The line A-B depicted in fig. 1(a, b and c) represents the dilution of Miglyol 812/Imwitor 988 ratio of 5:5 with increasing concentration of Cremophor RH40. It shows that the maximum amount of Cremophor RH40 that can be used to formulate isotropic blends is $20 \%, 40 \%$ or up to $90 \%$ at temperatures $15^{\circ} \mathrm{C}, 25^{\circ} \mathrm{C}$ and $45^{\circ} \mathrm{C}$, respectively. This suggests that reduction of the temperature expands the area of immiscibility and prompts crystallization of Cremophor RH40 which could result in drug precipitation. This nullifies the purpose of lipid formulations which are designed to improve the dissolution rate of poorly watersoluble drugs and thus enhance absorption. Therefore, as it has been shown, the choice of Cremophor RH40 limits the range of acceptable oil formulations that can be used to produce microemulsion systems. The use of co-solvent in these systems might improve the range of reliable oil systems. Yet this, however, raises the issue of losing the solvent capacity of these formulations on dilution of the co-solvent in the lumen of the gut which might ensue in crystallization of the drug. Alternatively, to screen for other surfactants that could replace Cremophor RH40 in an attempt to expand area of miscibility and hence avoids precipitation of formulation due to variations in the ambient temperature; in particular the liquid surfactants such as, Cremophor EL, polysorbate $80 / 20$ or Tagat 02 .

Fig. 2 shows the phase equilibrium in a three-component system of Miglyol 812/Imwitor 988 and Cremophor EL (polyoxyethylene-(35)caster oil). In contrast to the oil systems containing Cremophor RH 40 (fig. 1), the ternary phase diagram depicted in fig. 2 displays a huge area of miscibility in which, Cremophor EL and Miglyol 812 show partial miscibility as there is only one bimodal curve. The phase diagram depicted in fig. 2 reveals similar areas of phase equilibrium as the ternary oil mixtures which contain Cremophor RH 40 at $45{ }^{\circ} \mathrm{C}$ (fig. 1c). This suggests that the waxy nature of the surfactant is what causes the crystallization of these systems containing Cremophor RH40 and thus restricting the range of oil systems which can be fabricated. Cremophor RH40 is a waxy material at room temperature as it has a high melting point of $\approx 40$ ${ }^{\circ} \mathrm{C}$ and thus it restricts the range of oil mixtures which can be used in the blend. It also implicates the scale-up production of lipid formulations as special considerations are needed to handle and process a molten formulation on automated equipment. Solidification of the lipid system and thus drug precipitation can also occur during processing and storage due to variations in the environmental temperature. Therefore, in order to circumvent the crystallization of monoglycerides and/or highly ethoxylated 
surfactant molecules as in the case of Cremophor RH40, Cremophor EL can be a good alternative. Especially, if we know that Cremophor EL which is obtained by reacting ethylene oxide with caster oil in a molar ratio of 35 moles to 1 mole, is the liquid form of Cremophor RH40 (polyoxyethylene-(40)-hydrogenated caster oil) with slightly lower HLB values (HLB, between 12 and 14) as it contains less ethoxy residues per molecule. Therefore, comparable mean emulsion droplet diameter (MEDD) profiles would be anticipated from emulsification of oil systems containing either Cremophor RH 40 or EL.

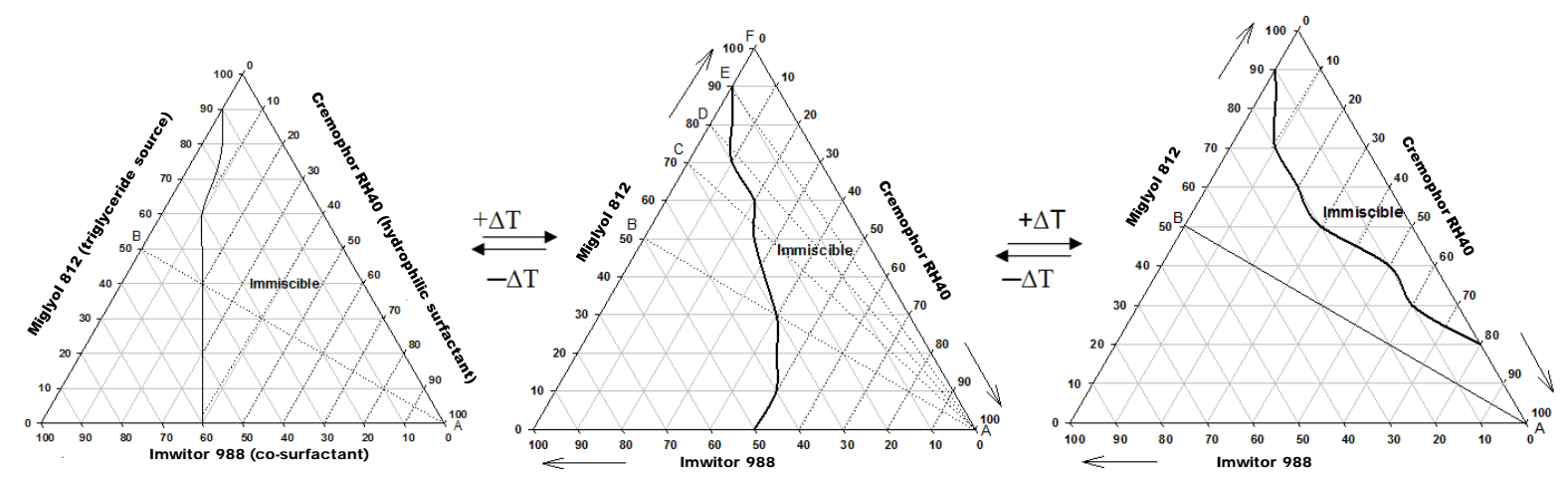

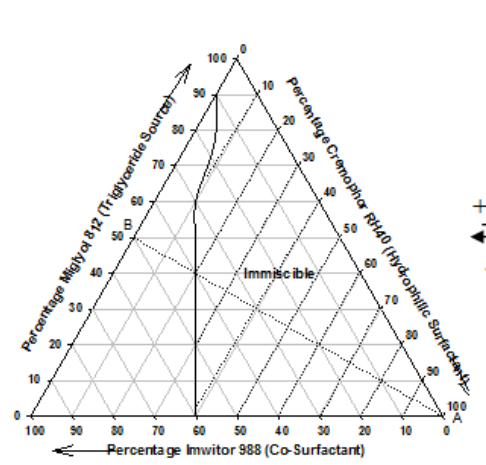

(a)

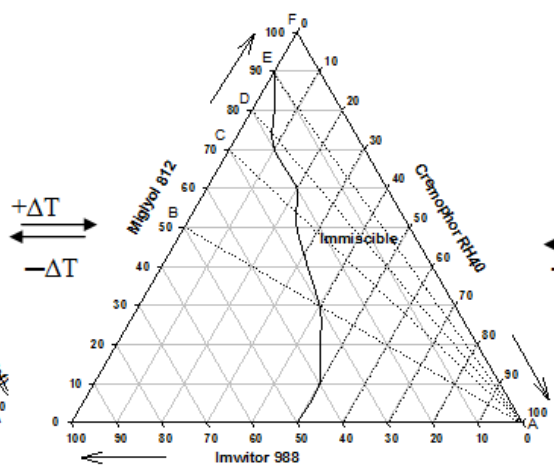

(b)

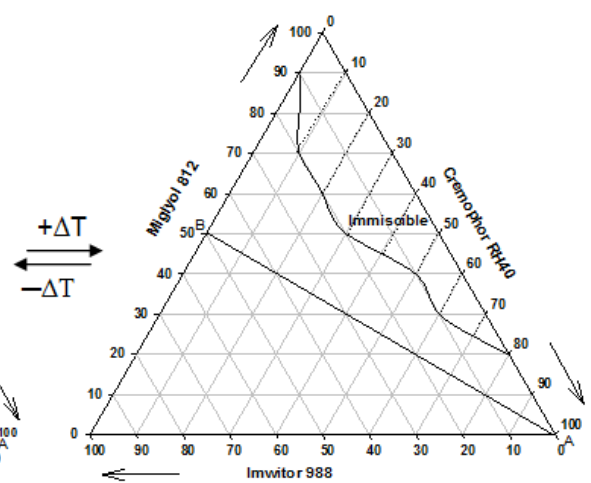

(c)

Fig. 1: The phase equilibrium in a three-component system for miglyol 812/Imwitor 988-Cremophor RH40 formulation under various isothermal conditions: (a) $15^{\circ} \mathrm{C}$ (b) $25^{\circ} \mathrm{C}$ (c) $45^{\circ} \mathrm{C}$

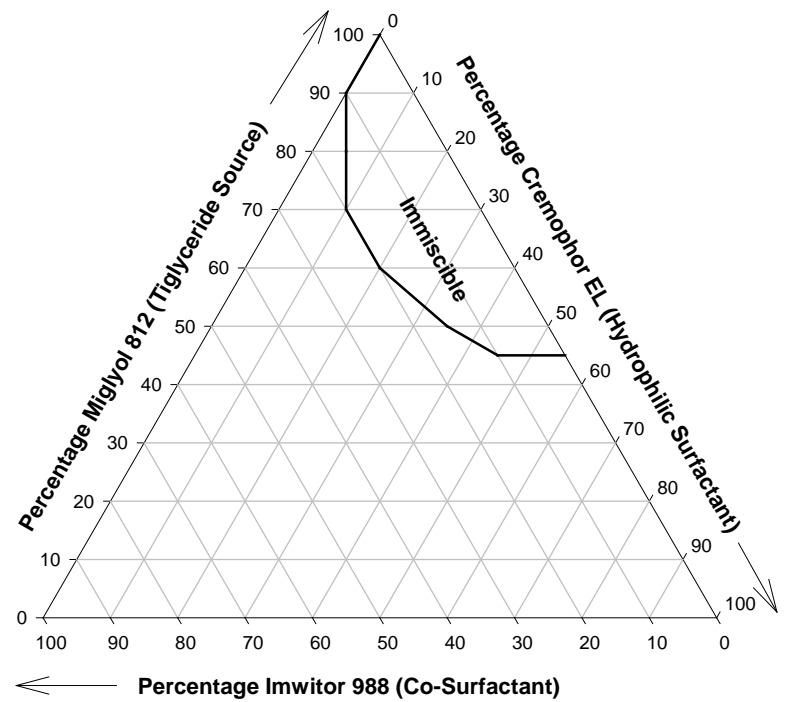

Fig. 2: Ternary phase diagram for Miglyol 812/Imwitor 988-Cremophor EL system displaying miscibility for formulations of various compositions

\section{Emulsification performance of oil systems}

In vitro particle size distribution analysis is one of the most important means to evaluate the stability of emulsions and also its in vivo fate after oral administration of the pre-concentrate, that is, a drug-surfactant-oil mix. Fig. 3 and 4 display the effect of surfactant concentration and oil: cosurfactant ratios of Miglyol 812/Imwitor 988 on the emulsification performance of Miglyol 812/Imwitor 988Cremophor RH40 lipid system as determined by the mean emulsion droplet diameter (MEDD). Oil systems containing Miglyol 812, 
Miglyol 812/Imwitior (9:1) or (8:2) blended with Cremophor RH40 at room temperature show either complete immiscibility or isotropic single phase oil mixtures with very limited concentration of Cremophor RH40<10\% w/w (fig. 1b, lines A-F, A-E and A-D). Hence, these oil mixtures were excluded from the emulsification study. On the other hand, for oil blends of Miglyol 812/Imwitor (7:3), Cremophor RH40 was included at a concentration below $25 \%$ $\mathrm{w} / \mathrm{w}$ lest using more surfactant in the system will ensue in phase separation due to crystallization, see fig. $1 \mathrm{~b}$ (line A-C). Generally, as depicted in fig. 3, the mean emulsion droplet diameter for Miglyol 812/Imwitor 988-Cremopho RH40 system decreased with increasing surfactant concentration at all Miglyol 812/Imwitor 988 ratios. Such a decrease in droplet size may be due to the availability of more surfactant to stabilize the oil-water interface. Furthermore, the decrease in the droplet size behavior reflects the formation of a better close-packed film of the surfactant at an oil-water interface which stabilizes the oil droplets [18]. Yet, the emulsification of Miglyol 812/Imwitor 988 blends of 7:3 ratio at surfactant content up to $20 \% \mathrm{w} / \mathrm{w}$, which is the maximum concentration to avoid crystallization, did not affect the droplet size significantly and thus produced dispersions with high MEDD values. However, with increasing the cosurfactant content (Imwitor 988) in the Miglyol 812/Imwitor 988-Cremophor RH40 system, the droplet size decreased substantially. This effect, however, is up to a point beyond which further increment of the co-surfactant would increase the MEDD values and thus more surfactant is needed to obtain equivalent MEDD values. Optimum dispersions of near optical clarity which were classified as self-micro-emulsifying systems were obtained at Miglyol 812/Imwitor 988 ratios of 6:4 or 5:5 (1:1) at Cremophor RH40 concentrations $\geq 15 \% \mathrm{w} / \mathrm{w}$ with minimum MEDD values of around $30 \mathrm{~nm}$ at a surfactant concentration of $30 \% \mathrm{w} / \mathrm{w}$. Nonetheless, any further increase in the cosurfactant content as when the system had 7 parts of Imwitor 988 (Miglyol 812/Imwitor 988) (3:7) MEDD value significantly increased and at least more $20 \% \mathrm{w} / \mathrm{w}$ of Cremophor $\mathrm{RH} 40$ is required to obtain clear dispersions. This indicates that regardless of Miglyol/Imwitor 988 ratio in the oil blends, microemulsions can still be obtained provided higher surfactant concentration is used. Yet, this raises a serious problem of damage to the gastrointestinal mucosa, as these systems contain a relatively large amount of surfactants. Nonetheless, contour plot for the emulsification performance of Miglyol 812/Imwitor 988-Cremophor RH40 system (fig. 4) shows an optimum blend of Miglyol 812/Imwitor 988 at 1:1 ratio which has produced the finest dispersions. A decrease in MEDD was observed with an increase in cosurfactant concentration from $30 \%$ to $50 \%$, after which the MEDD was slightly increased. Similar observations have been reported [19-20] where a further increase in cosurfactant concentration increased the droplet size. This was demonstrated by Gao et al. [20] using microemulsion systems containing Captex-355 as an oil, Cremophor EL as a surfactant, Transcutol as a cosurfactant and saline. This is also confirmed in a recent study by Hasan et al. [4] using formulation consisting of \{Miglyol 812/Imwitor 988\} and Tagat TO. Optimized self-microemulsifying system with aqueous dispersions of relatively lower MEDDS values of $\approx 50 \mathrm{~nm}$ was obtained on including $30 \% \mathrm{w} / \mathrm{w}$ Imwitor 988 in the oil blend. Further incorporation of more Imwitor 988 in the oil mix ensued in increases in MEDD values hence, optimum robust self-micro emulsifying lipid system of Miglyol 812/Imwitor 988-Tagat TO was fabricate at ratios of $70(70 / 30) 30)$. It is important to note here that the need for a cosurfactant is related to the fact that each head group unit is hydrophilic. Therefore, the addition of an extra unit considerably increases the hydrophilicity of the surfactant and hence, it is made harder to achieve the correct balance of the hydrophobic and hydrophilic portions of the surfactant required for the production of a microemulsion. Instead, this balance has to be achieved by the use of a cosurfactant [21]. The addition of surfactant to the microemulsion systems causes the interfacial film to condense and to be stable, while the addition of cosurfactant causes the film to expand [22]. When a cosurfactant is added to the system with the surfactant, it lowers the interfacial tension, fluidizes the hydrocarbon region of the interfacial film and decreases the bending stress of the interface [23]. As Imwitor 988 is polar oil due to the glycerol mono-caprylate content $(\approx 50 \%)$, the polarity of oil droplets is optimized at a certain ratio of Miglyol 812/Imwitor 988 after which, any further increase in the Imwitor 988 content would affect the hydrophilic-lipophilic balance (HLB) of the system and consequently the emulsification is affected. The role of Imwitor 988 as a co-surfactant in stabilizing $0 / \mathrm{W}$ interface and hence reducing MEDD values of aqueous dispersions is illustrated in fig. 5 . It is suggested by Hasan et al. [4] that Imwitor 988 can penetrate into the void spaces among surfactant molecules in the surfactant film around the oil droplet which can result in increasing interfacial fluidity, lowering the interfacial tension and thus stabilizing $0 / \mathrm{W}$ interface. When saturation around oil droplets at the $0 / \mathrm{W}$ interface is achieved at optimum concentrations of co-surfactant in the oil mixture, decrease in MEDD profiles is observed. Yet, on further including more Imwitor 988 which has limited solubility in water at this point particle size of the resultant dispersion is increased as the excess of Imwitor 988 which has no place to occupy in the surfactant film around droplets of oil disperses in the aqueous phase.

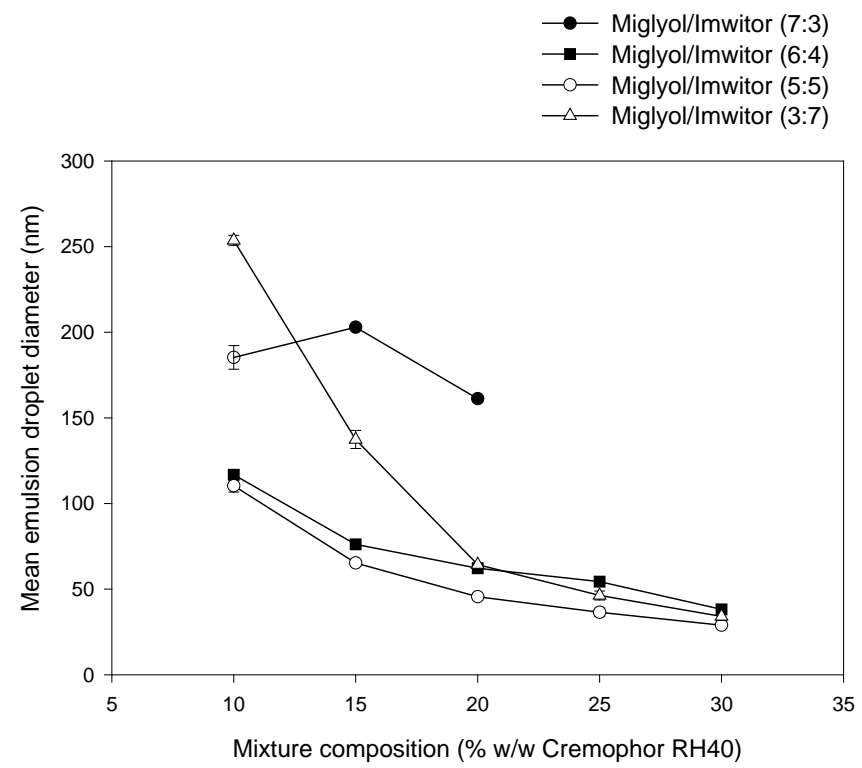

Fig. 3: Mean emulsion droplet diameter (MEDD) profiles for self-emulsified systems containing different ratios of Miglyol 812/Imwitor 988 and increasing concentration of cremophor $\mathbf{R H 4 0}$. Bars represent standard errors $(n=3)$ 


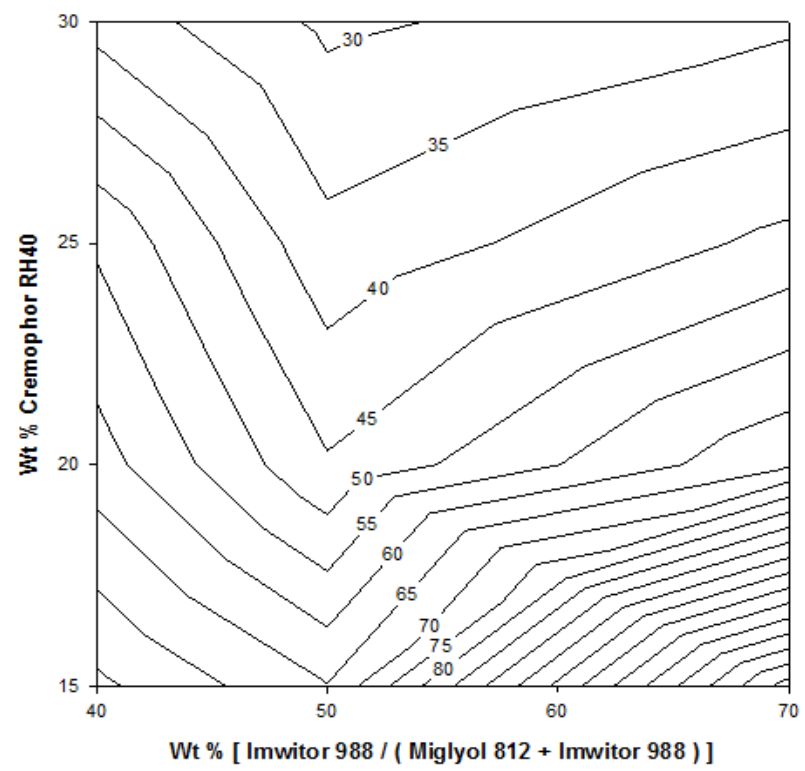

Fig. 4: Contour plot representations of MEDD data for the emulsification of Miglyol 812/Imwitor 988-Cremophor RH40 system as a function of surfactant concentration and the ratio of Imwitor 988/Miglyol 812 in the oil blend

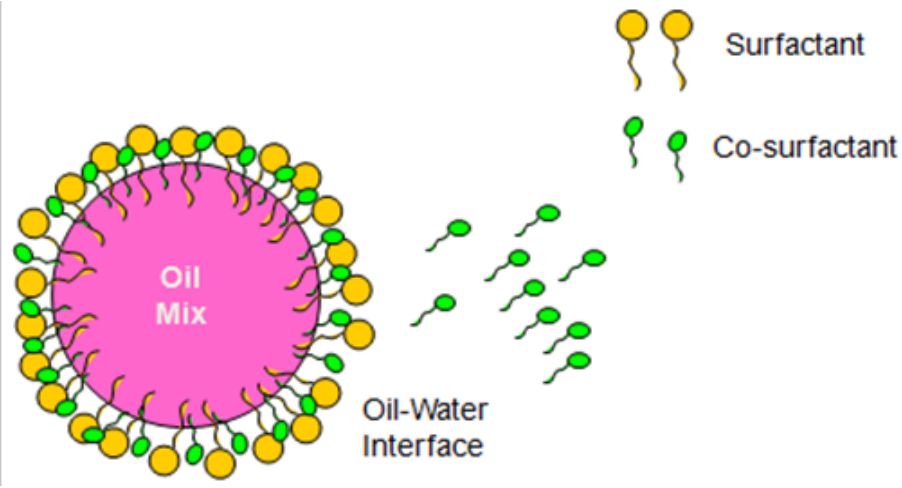

Fig. 5: Effect of the co-surfactant and surfactant in stabilizing the $0 / \mathrm{W}$ interface

However, in a study by Kawakami et al. [24, 25], they concluded that surface tension and polarity measurements of oil blends did not correlate with the system ability to form microemulsions as determined by the amount of oil solubilized in the surfactant-water mixtures. They demonstrated that the most effective mixing ratio to mimic the solubilization behaviour was 1:1 of glycerol monocaprylic ester (MCG) and propyleneglycol dicaprylic ester (DCPG), although the later was hardly solubilized in any surfactant solutions. Yet, they offered one possible assumption whereby the DCPG phase may be enclosed in a shell of the MCG rich phase hence MCG molecules may penetrate into the surfactant layer as the penetration of polar oils into surfactant layer has been observed [26, 27]. This will be reflected upon when we study the mechanistic processes involved in the emulsification of Miglyol 812/Imwitor 988-Cremophor RH40 system. On the other hand, in this investigation the emulsification of Imwitor 988 (Glycerol mono-/di-caprylate $\{1: 1\}$ )-Cremophor RH40 system (i.e. without any Miglyol 812) produced dispersions with inconsistent and high MEDD values which suggest the need to include medium chain triglyceride (MCT) in the formulation. Apparently, this contrasts results from Kawakami et al.[24] in the case of Cremophor RH40 whereby maximum solubilization occurred at MCG/DCPG ratio of 1:1. This could be attributed to the fact that in their study the solubilization behaviour of ternary oil mix MCG, DCPG and MCT was not optimized as they investigated these ester oils each one alone or as a binary mix. Also, they have used one surfactant concentration that is, $10 \% \mathrm{w} / \mathrm{w}$ which appears to be very small when considering forming $\mathrm{o} / \mathrm{w}$ microemulsions.
In an attempt to prevaricate the crystallization tendency of Cremophor RH40 in the pre-microemulsion concentrate and thus expands the range of mixtures which can be used, alternative surfactants were investigated such as, Cremophor EL, Crillet 4, Crillet 1 and Tagat 02 . The emulsification profiles with contour plot for Miglyol 812/Imwitor 988-Cremophor EL are depicted in fig. 6 and 7. Cremophor EL (polyoxyethylene-(35)-caster oil) is considered to be the liquid form of Cremophor RH40 (HLB, 14-16) yet with lower HLB value (12-14) due to less ethoxylation number. This has reflected on the area of miscibility as depicted by the ternary phase diagram (fig. 2) which offers wide range of potential pre-microemulsion mixtures without restriction on the amount of surfactant to be included. As illustrated in fig. 6, the emulsification profiles of Miglyol 812/Imwitor 988-Cremophor EL have shown trends similar to formulations containing Cremophor RH40 whereby droplet size is controlled by the surfactant concentration and the oilcosurfactant ratio. With increasing the amount of surfactant or cosurfactant in the system, smaller MEDD could be obtained. Yet, the increase in the cosurfactant-oil ratio is up to a point beyond which the polarity of oil droplets is enhanced and thus the HLB of the oil system becomes out of the range to produce microemulsions and consequently, the MEDD is increased. As depicted in fig. 6, the emulsification performance of Miglyol 812/Imwitor 988 (7:3) using Cremophor EL has produced dispersions with high MEDD values. Equivalent MEDD profiles were obtained at 812/Imwitor 988 (6:4), (5:5) or (3:7) using Cremophor EL at a concentration of $\geq 15 \% \mathrm{w} / \mathrm{w}$. This is in contrast to the variations in the emulsification profiles of Miglyol 812/Imwitor 988 (6:4), (5:5) or (3:7) using Cremophor 
RH40 (fig. 3). Nonetheless, it is evident from contour representations of the MEDD data depicted in fig. 7 that optimum MEDD profiles are obtained at co-surfactant (Imwitor 988) concentration extended from $40-70 \% \mathrm{w} / \mathrm{w}$ in the oil blend as flat contour lines are observed at those co-surfactant ratios. Unlike the minimum trough observed at Imwitor 988 concentration of $50 \%$ $\mathrm{w} / \mathrm{w}$ in the contour representation of the MEDD for Miglyol 812/Imwitor 988-Cremophor RH40 system (fig. 3). Minimum MEDD of $30 \mathrm{~nm}$ at approximately $35 \% \mathrm{w} / \mathrm{w}$ Cremophor EL has extended over Imwitor 988 weight percentage from $50-70 \%$. This broad range of cosurfactant amount in the oil blend which has produced microemulsion systems with no variations in the emulsification profiles is attributable to the relatively low HLB value of Cremophor EL comparing to RH 40. As discussed earlier, the use of cosurfactant normally adds to the total polarity of oil droplets and hence increases the HLB of the system. If the surfactant has already high HLB value as in the case of Cremophor RH40 (HLB between 14 and16), the amount of cosurfactant that is needed to obtain an HLB value of the oil mix within the range for producing microemulsion systems is limited. However, for Cremophor EL which has relatively lower HLB value (between 12 and 14), the range of cosurfactant that is required to produce an oil mix with an HLB value which is within the range to obtain fine dispersions is widened. Last but not least, provided optimum oil blends are used, Cremophor EL offers a good alternative to Cremophor RH40 for the formulation of SMEDDS, see table 1. In a study by Gao et al. [20] using Captex $355^{\circledR}$ as an oil, Cremophor EL $^{\circledR}$ as a surfactant, Transcutol ${ }^{\circledR}$ as a cosurfactant and saline, microemulsion systems were optimized at Cremophor EL ${ }^{\circledR}:$ Transcutol ${ }^{\circledR}:$ Captex 355 ${ }^{\circledR}$, 10:5:4 i.e. oil-cosurfactant ratio of approximately $1: 1$ with $50 \%$ surfactant. Though the oil-cosurfactant ratio of the oil blend agrees with our findings yet the use of high content of the surfactant in his system raises serious toxicity issues. Similar optimal ratio oilcosurfactant ratio (1:1) was also in the formulation of SMEDDS composed of Labrafac: oleic acid: Cremophor EL: Transcutol $\mathrm{P}=40$ : 10: $40: 10(\mathrm{w} / \mathrm{w})[28]$.
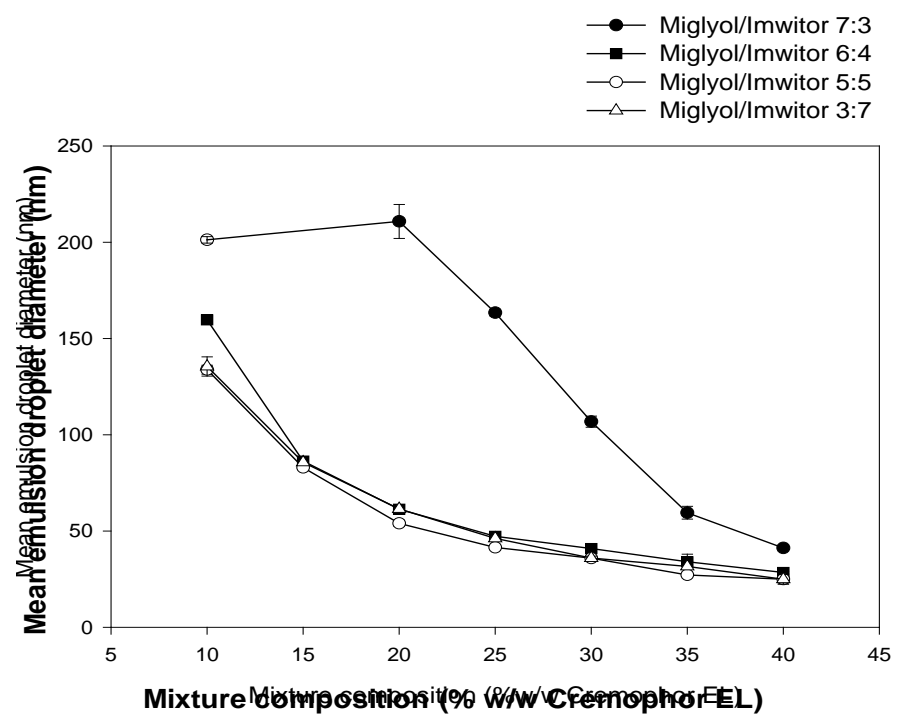

Fig. 6: Emulsification profiles of self-emulsified systems containing different ratios of Miglyol 812/Imwitor 988 and increasing concentration of Cremophor EL. Lipid formulations were emulsified in water at $37^{\circ} \mathrm{C}$ for $15 \mathrm{~min}$. MEDD values were measured by photon correlation spectrometer (PCS). Bars Represent Standard Errors $(n=3)$

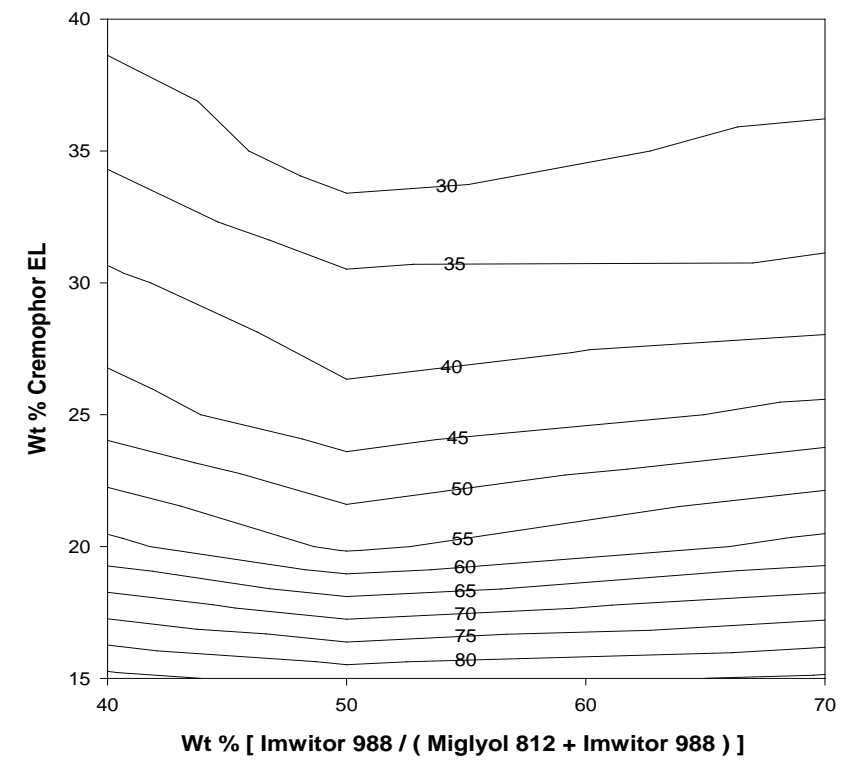

Fig. 7: Three-dimensional graph and contour plot representations of MEDD data for the emulsification of Miglyol 812/Imwitor 988Cremophor EL system as a function of surfactant concentration and the ratio of Imwitor 988/Miglyol 812 in the oil blend 


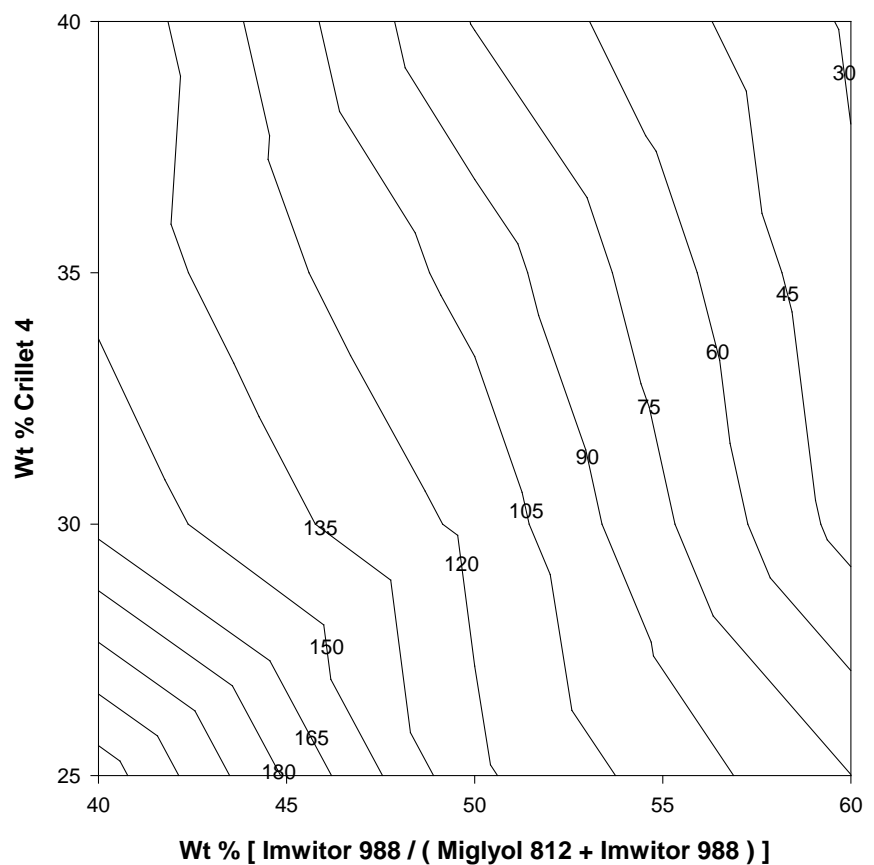

Fig. 8: Three-dimensional graph and contour plot representations of MEDD data for the emulsification of Miglyol 812/Imwitor 988-Crillet 4 system as a function of surfactant concentration and ratio of Imwitor 988/Miglyol 812 in the oil blend

Table 1: Comparison of emulsification performance for microemulsion systems prepared using various hydrophilic surfactants at various optimal oil: Co-surfactant ratios as determined by droplet size measurement. $(n=3)$

\begin{tabular}{llll}
\hline Formula & $\begin{array}{l}\text { Miglyol/Imwitor (5:5)- } \\
\text { Cremophor RH40 }\end{array}$ & $\begin{array}{l}\text { Miglyol/Imwitor (5:5)- } \\
\text { Cremophor EL }\end{array}$ & $\begin{array}{l}\text { Miglyol/Imwitor (4:6)- } \\
\text { Crillet 4 }\end{array}$ \\
\hline $\begin{array}{l}\text { Surfactant Wt } \\
\text { \% }\end{array}$ & MEDD (nm) & $\begin{array}{l}\text { Miglyol/Imwitor (4:6)- } \\
\text { Tagat O }\end{array}$ \\
\hline 10 & $110.40 \pm 3.70$ & $133.80 \pm 2.30$ & Off range \\
15 & $65.25 \pm 0.21$ & $83.00 \pm 0.42$ & Off range \\
20 & $45.55 \pm 0.78$ & $54.00 \pm 1.60$ & $220.33 \pm 4.65$ \\
25 & $36.50 \pm 2.40$ & $41.50 \pm 0.57$ & $75.10 \pm 0.40$ \\
30 & $28.95 \pm 1.20$ & $35.90 \pm 0.99$ & $38.80 \pm 1.00$ \\
35 & $27.2 \pm 0.00$ & $27.20 \pm 0.00$ & $32.80 \pm 0.20$ \\
40 & Unstable & $25.00 \pm 2.50$ & $28.00 \pm 1.30$ \\
\hline
\end{tabular}

Table 2: Effect of surfactant hydrophilicity on the optimum weight ratio of oil in the oil-surfactant blend for various microemulsion systems, surfactants with HLB values<12 are considered to be lipophilic [29]

\begin{tabular}{lll}
\hline Surfactant type & HLB of surfactant & Wt \% of Miglyol in (Miglyol/Imwitor) \\
\hline Tagat TO & 11 & $70 \%$ \\
Cremophor EL & $12-14$ & $30-60 \%$ \\
Cremophor RH40 & $14-16$ & $30-60 \%$ \\
Crillet 4 & 15 & $40 \%$ \\
Tagat O2 & 15 & $40 \%$ \\
\hline
\end{tabular}

Moreover, in an attempt to screen for more self-micro-emulsifying systems using blends of Miglyol 812/Imwitor 988 new hydrophilic surfactants were investigated in this study including; Crillet 4 (polyoxyethylene(20) sorbitan monooleate), Crillet 1 (Polyoxyethylene-(20)-sorbitan monolaurate) and Tagat 02 (polyoxyethylene-(20)-glyceryl monooleate. Optimal self-microemulsifying systems were obtained at Miglyol 812/Imwitor 988 ratio of $4: 6$ in the case of using Crillet 4 and Tagat 02 . Yet, Crillet 1 has shown no potential for pre-microemulsion formulations hence it has produced dispersions with high MEDD values at all Miglyol 812/Imwitor ratios (data not shown). The emulsification of Miglyol 812/Imwitor 988 (7:3), (3:7) and (1:9)-Crillet 4 have produced selfemulsified drug delivery systems (SEDDS) with MEDD values between 1 and $5 \mu \mathrm{m}$ (data not shown). Similar to oil systems containing either Cremophor RH40 or EL (fig. 3 and 6, respectively); increasing the surfactant concentration or the cosurfactant to oil ratio in the Miglyol 812/Imwitor 988-Crillet 4 system reduces the MEDD values. Yet, the increase of the co-surfactant in the oil blend is also to a point beyond which further increment would ensue in an increase in the MEDD values. As the the contour plot for Miglyol 812/Imwitor 988-Crillet 4 system depicted in fig. 8, microemulsion systems are optimised at Miglyol 812/Imwitor 988 ratio of $4: 6$. The contour plot representation of the MEDD data for this system shows a minimum trough of $30 \mathrm{~nm}$ at a cosurfactant-oil ratio of $60: 40$ and using approximately $35 \% \mathrm{w} / \mathrm{w}$ Crillet 4 i.e. 65(60/40)35, see table 1 . This ratio of oil blend was also found to be the optimum in a study by Kawakami et al. [24]. They found that the combination of MCG with MCT at the ratio of 6:4 in the case of Tween 80 (equivalent to Crillet 4) was effective to achieve maximum oil solubilization. It is important to note here that the use of either Cremophor RH40 or EL 
has been able to produce SMEDDS with a wider range of Miglyol 812/Imwitor blends than in the case of Crillet 4 (polysorbate 80). Hence Cremophor RH40 and EL are caster oil derivatives, these results suggest that the type and structure of the lipophilic moiety is of paramount importance to the self-emulsification process. Furthermore, the freedom of chain movement and orientation imparted by the removal of the sorbitan ring should aid in the ease of molecular interactions [30].

In contrast to oil mixtures containing Crillet 4, Miglyol 812/Imwitor 988-Crillet 1 has shown no potential for pre-microemulsion formulations hence it has produced dispersions with high MEDD values at all Miglyol 812/Imwitor ratios (data not shown). This was also observed by Kawakami et al. [24] whereby Tween 80 (equivalent to Crillet 4) was able to solubilise $23 \% \mathrm{w} / \mathrm{w}$ of oil mixture composed of 1:1 DCPG and MCG vis-à-vis $1 \%$ in the case of Tween 20 (equivalent to Crillet 1). This might be due to the fact that Crillet 1 (Polyoxyethylene-(20)-sorbitan monolaurate) has relatively higher HLB value (16.7) than Crillet 4 (polyoxyethylene-(20)sorbitan monooleate, HLB 15.0). This indicates that in order to

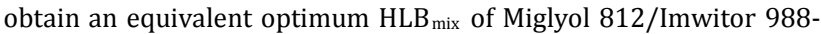
Crillet 4 system for producing microemulsion systems, Crillet 1 needs to be mixed with oil blends high in Miglyol 812 content of at least $\geq 70 \%$. Yet, according to the ternary equilibrium phase diagram for Miglyol 812/Imwitor 988-Crillet 1, these systems do not form stable isotropic one phase concentrates. Furthermore, it was surmised that the presence of oleic acid residues as the major constituent of the hydrophobic portion of the surfactant molecule were essential for mixtures with Miglyol 812 to exhibit good emulsification [30]

The emulsification profiles of Miglyol 812/Imwitor 988 at ratios of (6:4) or (5:5) using Tagat 02 (polyoxyethylene-(20)-glyceryl monooleate, $\mathrm{HLB}=15$ ) produced MEDD profiles comparable to the emulsification of same oil mixtures but containing Crillet 4 (data not shown). Furthermore, similar to blends containing Crillet 4, optimal microemulsion systems were obtained for Tagat 02 using blends of Miglyol $812 /$ Imwitor 988 at $4: 6$. Yet, as table 1 suggests, at surfactant concentration $<30 \% \mathrm{w} / \mathrm{w}$, oil mixtures containing Crillet 4 appear to be more emulsifiable than Tagat 02 . Yet, both surfactants at a concentration $\geq 35 \% \mathrm{w} / \mathrm{w}$ produced fine dispersions with almost equivalent MEDD values. These results have demonstrated that the emulsification performance of oil systems containing either Tagat 02 or Crillet 4 have shown a comparable trend with slight variations. This could be attributed to the fact that both surfactants have same HLB value (15) and more importantly similar chemical structure, yet with the lack of sorbitan ring in the case of Tagat 02. This suggests that the sorbitan nucleus structure in the case of polyoxyethylene monoalkyl esters is not the major factor to determine good self-emulsification with triglyceride oils. Similar observations were made by Wakerly [30], whereby Crillet 11 (polyoxyethylene-(4)-sorbitan mono-laurate) gave a performance similar to alcohol ethoxylates of equivalent HLB. Further evidence was also demonstrated from studies with Atlox $1045 \mathrm{~A}$, an ethoxylated sorbital (opened sorbitan ring) ester of mainly oleic acid (HLB 13.2) [30]. This surfactant exhibited good selfemulsification with Miglyol 812 and had an equivalent HLB value to Crillet 11. These results have shown that Cremophor RH40 is a good surfactant for a formulation of SMEDDS yet is not a special case. It is possible to obtain very fine dispersions with other non-ionic surfactants such as, Cremophor EL, polysorbate 80 or Tagat 02, provided right oil-cosurfactant ratio is used to optimise the performance of SMEDDS, see table 1 . Nonetheless, as table 1 suggests at surfactant concentrations $\leq 15 \% \mathrm{w} / \mathrm{w}$ Cremophor RH40 or Cremophor EL has shown relatively better emulsification performance and thus maximum oil solubilization than Tagat 02 or Crillet 4 .

\section{Mechanistics of the emulsification process}

General considerations of the putative mechanisms which have been proposed to explain spontaneous and self-emulsification processes have been discussed thoroughly in many reports [3-4, 30-33]. In practice, disruption of the oil-water interface is caused by penetration of water into the formulation through the network of aqueous channels or diffusion of hydrophilic components such as, cosolvents and hydrophilic surfactants away from the formulation into the aqueous phase see fig. 9. Both of these phenomena can be studied using equilibrium phase diagrams, which alongside with droplet size analysis can allow the optimisation performance of selfemulsified systems. The precise mechanisms of emulsification remain the subject of speculation. Nonetheless, studies by Wakerly [30] and Pouton [31] using either Tagat TO or Tween 85 with Miglyol 812 have identified an empirical link between selfemulsification, liquid crystal formation, phase inversion temperature and enhanced water solubilization by oily systems. Nevertheless, recent studies by Hasan et al. [4] have demonstrated that the inclusion of medium C8/C10 mono/diglycerides (Imwitor 988) in Miglyol 812-Tagat T0 system has transformed dynamic equilibrium phase map of the oil system on interaction with water. Thus, the enhancement of water solubilization ( $\mathrm{L}_{2}$ phase) was of paramount importance to the mechanistics of emulsification for type II lipid class systems. Furthermore, the enhanced water solubilization is linked to ease of emulsification and low droplet size [34]. This also appears to be true for type III systems investigated here which contain hydrophilic materials (surfactants with HLB $>12$ and/or water-soluble cosolvents). For these systems, where a hydrophilic surfactant or cosolvent is present, rapid emulsification occurs by a mechanism which could be delineated as 'diffusion and stranding' (fig. 9b). Diffusion of water into the oil phase converts it to $\mathrm{w} / \mathrm{o}$ microemulsion ( $\mathrm{L}_{2}$ phase) then there will be a significant migration of material which partitions and becomes diluted into the bulk aqueous phase [35]. This hydrophilic material dissolves the water-insoluble component into the aqueous phase as a solubilized system forming a bicontinuous microemulsion. On further diffusion, the concentration of the hydrophilic component becomes too dilute to fully solubilise the oil and consequently the water-insoluble oil separates as a second phase-forming an oil droplet. In order to obtain uniformly small oil droplets in water, the pre-concentrate oil mixture has to be either slightly lipophilic or hydrophilic depending on the hydrophilic-lipophilic balance (HLB) of the surfactant. Therefore, for systems containing lipophilic surfactants such as Tagat TO (HLB 11) the injected drop has to be slightly lipophilic; i.e., the oil to cosurfactant ratio has to be slightly greater than that of the excess oil phase in equilibrium with bicontinuous microemulsion [33]. Weight ratio of oilto-cosurfactant at 70/30 has been optimum for Tagat TO system, see table 2. On the other hand, in the case of hydrophilic surfactants (HLB 212) such as; Cremophor RH40, EL, Crillet 4 or Tagat 02, oil blend (oil/cosurfactant) has to be slightly hydrophilic which means less weight ratio of oil (Miglyol 812) needs to be used, see table 2. Thus, for some optimal range of initial drop compositions, an emulsion of small oil droplets in water can be achieved.

In order to give insight into the mechanistic process of emulsification in type III systems, ternary equilibrium phase diagrams on dilution with water were constructed. Furthermore, emulsification profiles as determined by droplet size measurement were also analyzed in the view of equilibrium phase behaviour study. Miglyol 812/Imwitor 988-Cremophor RH40 system was selected for this phase study as an archetypal example of type III formulations which forms fine dispersions. The triangular equilibrium phase behaviour diagram for Miglyol 812/Imwitor (5:5)-Cremophor RH40 system on dilution with water is depicted in fig. 10. The oil blend of Miglyol 812/Imwitor 988 at ratio of 5:5 was first investigated here as it was found to be the optimum for selfmicro-emulsification in the case of Cremophor RH40. As fig. 10 displays, Miglyol 812/Imwitor $988 \quad(5: 5)$ blend is virtually immiscible with water as it forms two phase system $\left(\mathrm{L}_{1}+\mathrm{L}_{2}\right)$. On the other hand, Cremophor RH 40 as a hydrophilic surfactant with HLB value of 14-16 is soluble in water. Therefore, on aqueous dilution, increasing the oil content in the formulation results in expansion of the $\mathrm{L}_{1}+\mathrm{L}_{2}$ region and consequently, more surfactant is needed to homogenize the system into isotropic mixtures $\left(\mathrm{L}_{2}\right.$ or $\left.\mathrm{L}_{1}\right)$. $\mathrm{L}_{1}+\mathrm{L}_{2}$ region reached a maximum when the system contained $45-65 \%$ $\mathrm{w} / \mathrm{w}$ oil and hence, minimum Cremophor RH40 concentration of $25 \% \mathrm{w} / \mathrm{w}$ was required to obtain clear mixtures close to the water apex in the ternary phase diagram, see fig. 10. Interestingly, this system at Cremophor RH40 ratio fraction in the oil mixture of $>20$ and on dilution with water between 20 and $50 \% \mathrm{w} / \mathrm{w}$ formed areas of various phases containing liquid crystalline material (LC, $\mathrm{L}_{2}+\mathrm{LC}$ and $\mathrm{L}_{1}+\mathrm{L}_{2}+\mathrm{LC}$ ) which intercepted $\mathrm{L}_{1}$ and $\mathrm{L}_{2}$ regions (see footnote in 
fig. 10 for phase description). Furthermore, an area of micellar solution $\left(\mathrm{L}_{1}\right)$ was obtained on further dilution with water $(>50 \%$ $\mathrm{w} / \mathrm{w}$ ). The ability of this system to solubilise the oil into micellar solution is attributable to the robust solubilizing capacity of Cremophor RH40 provided sufficient concentration is used. The LC phase and in particular the typical $\mathrm{LC}_{\mathrm{a}}$ is generally associated with self-emulsification. The LC phase is viscous and exhibits white birefringence. In contrast, the transparent liquid crystalline dispersion phase, denoted $\mathrm{LC}_{\mathrm{a}}$, differs from the $\mathrm{LC}$ phase in that it displays low viscosity and multicolored birefringence. The nature of the $\mathrm{LC}_{\mathrm{a}}$ is thought to consist of a dispersion of lamellar liquid crystal in $\mathrm{L}_{2}$ phase [36-37]. There has been no attempt in this phase study to differentiate between various types of LC phases, as their role in the mechanistics of emulsification for this system appears to be not crucial. Yet, the formation of LC phases after maximum solubilization of water (L2) of approximately $20 \%$ occurred, might have facilitated further penetration of water through the aqueous channels which resulted in further diffusion of the Cremophor RH40 away to the aqueous phase and consequently, the system became solubilized into micellar solution ( $\left.\mathrm{L}_{1}\right)$. The line (A-B) depicted in fig. 10 represents the dilution of Miglyol 812/Imwitor 988 (5:5) blend and Cremophor RH40 mixtures at the ratio of $70 / 30$ with water. The dilution of the initial oil mixture $\left(\mathrm{L}_{2}\right)$ with water would pass through $\mathrm{L}_{2} \rightarrow \mathrm{L}_{1}+\mathrm{L}_{2} \rightarrow \mathrm{L}_{1}+\mathrm{L}_{2}+\mathrm{LC}_{\mathrm{a}} \rightarrow \mathrm{L}_{1}$ phases. Therefore, it is likely that the MEDD profile for the previous system $(70(50 / 50) 30)$ which is presented in fig. 3 is considered to be the dilution of the micellar solution ( $\mathrm{L}_{1}$ phase) with water to give a final composition with relatively low MEDD values.

(a)

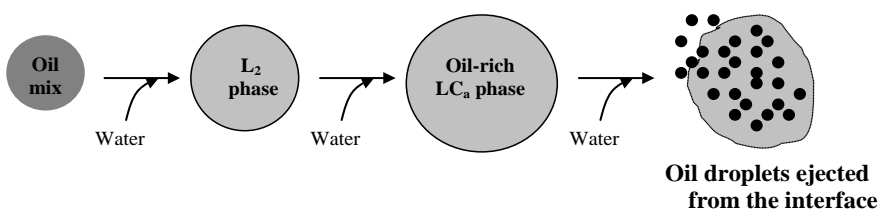

(b)

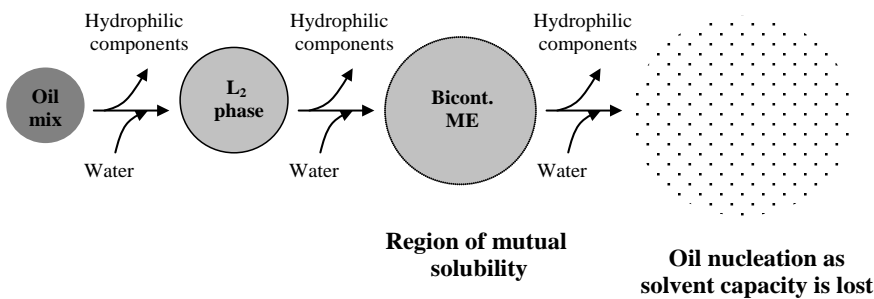

Fig. 9: Mechanistics of self-emulsification process; (a) Water-insoluble systems (eg. Type II SEDDS): penetration of water leads to the formation of liquid crystals at the oil-water interface which allow further penetration of water down aqueous channels, causing an increase in surface pressure and interfacial disruption which ensue in fine emulsion droplets to be exudated from the interface. (b) Systems containing a water-soluble component (Type III): 'diffusion and stranding' mechanism is attributed to the emulsification of these systems which can lead to very fine dispersions. As the solvent capacity is lost due to the diffusion of the hydrophilic component, oil and drug form a separate phase. Adapted from reference [4]

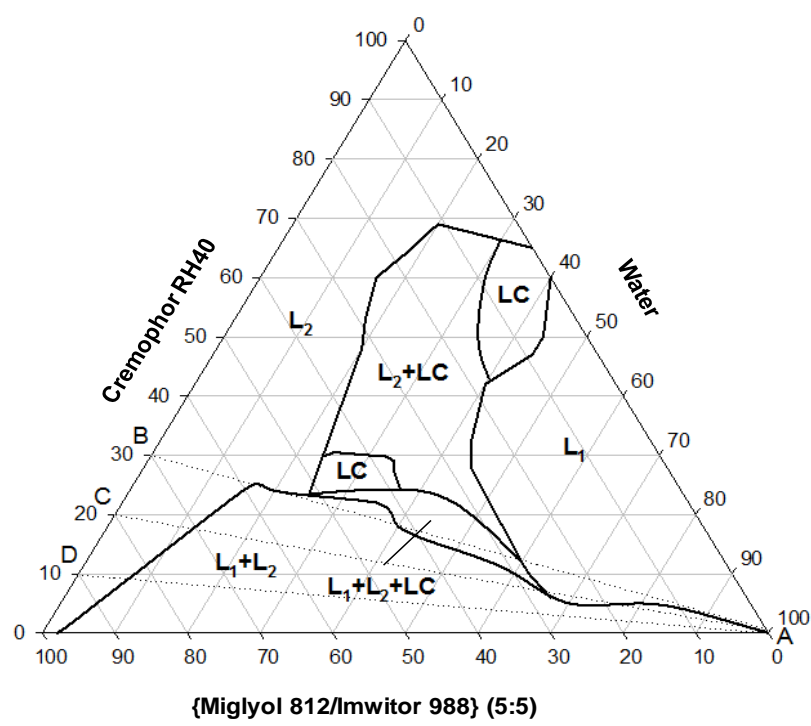

Fig. 10: Triangular equilibrium phase diagram for the Miglyol 812/Imwitor 988 (5:5)-Cremophor RH40-water system at 25 ${ }^{\circ} \mathrm{C}$. Lines A-B, A-C and A-D represent the dilution of Miglyol 812/Imwitor 988 (5:5) blend and Cremophor RH40 mixtures at ratios 70/30, 80/20 or

$90 / 10$, respectively, with water. Aqueous-based liquids are designated $L_{1}$, oil-based liquids $\left(L_{2}\right)$ and liquid crystal phases "white" birefringence (LC). Turbid mixtures, which tended to separate on storage into a water-rich phase and an oil-rich phase, were designated $\left(L_{1}+L_{2}\right)$ or $\left(L_{1}+L_{2}+L C\right)$ when liquid crystalline material was clearly present 


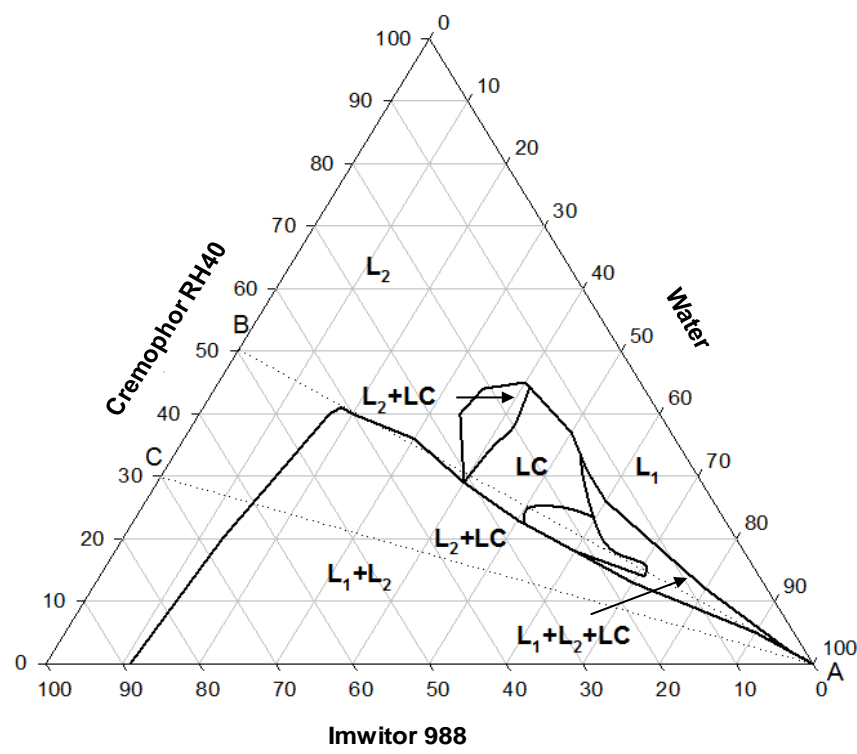

Fig. 11: Triangular equilibrium phase diagram for the Imwitor 988-Cremophor RH40-water system at $25^{\circ} \mathrm{C}$. Lines A-B and A-C represent the dilution of Imwitor 988 /Cremophor RH40 binary mixtures at ratios 50/50 and 70/30, respectively, with water

On the other hand, the emulsification of Miglyol 812/Imwitor 988 (5:5)-Cremophor RH40 at ratios of (90(50/50)10) depicted in fig. 3 considered to be the dilution of $\mathrm{L}_{1}+\mathrm{L}_{2}$ phase (fig. 10, line A-D). Therefore, it is anticipated for this system to produce high MEDD values. Nonetheless, increasing the surfactant ratio in the oilsurfactant pre-concentrate would, on aqueous dilution, shift the $\mathrm{L}_{1}+\mathrm{L}_{2}$ phase towards the micellar solution region $\left(\mathrm{L}_{1}\right)$ close to the water apex in the triangular phase diagram (lines A-D, A-C, and A-B, fig. 10), and consequently, fine dispersions are obtained. This is in agreement with the droplet size measurements depicted in fig. 3, whereby MEDD is reduced by increasing the surfactant concentration in the oil system. Furthermore, as the line A-B depicted in fig. 10 shows, Miglyol 812/Imwitor 988 (5:5)Cremophor RH40 system at a ratio of $70 / 30$ is thought to be the optimum for micro-emulsification in this system, which also agrees with the contour representation of the MEDD depicted in fig. 4.

In order to investigate the importance of triglyceride source (Miglyol 812 ) in the mechanisms of emulsification in type III systems, equilibrium phase behaviour for Imwitor 988-Crmophor RH40 system on dilution with water was studied and presented in fig. 11 . The ternary equilibrium phase diagram for Imwitor 988-Cremophor RH40-water system shows huge extension in the L1+L2 region with the comparison to the same system but containing Miglyol 812/Imwitor 988 at 1:1 ratio (fig. 10). For Imwitor 988-Cremophor RH40-water system, an optimum oil-tosurfactant ratio at 50/50 is required to transform two-phase mixtures into isotropic phases (L2 or L1) (line A-B, fig. 11) vis-à-vis 70/30 in the case of Miglyol 812/Imwitor (5:5)-Cremophor RH40 system (line A-B, fig. 10). On the other hand, the emulsification of Imwitor 988-Cremophor $\mathrm{RH} 40$ at ratio of 70/30 is considered to be the dilution of $\mathrm{L} 1+\mathrm{L} 2$ phase (line A-C, fig. 11) and hence it is anticipated for this system to produce relatively high MEDD values. This indicates that in order to obtain premicroemulsion concentrate in the case of Imwitor 988-Cremophor RH40 system more surfactant needs to be used which might raise toxicity issues. Therefore, including Miglyol 812 in the oil blend is important to obtain microemulsion systems in the case of type III lipid formulations. However, Miglyol 812 is required at optimum ratios to produce a preconcentrate of oil-cosurfactant-surfactant with right HLB mix for selfmicro-emulsification. Furthermore, in contrast to the extended areas which contained LC material in the case of Miglyol 812/Imwitor (5:5)Cremophor RH40-water system, limited areas of LC phases were observed in the Imwitor 988-Cremophor RH40-water system (fig. 10 and 11, respectively). This might be attributed to the solvent capacity of Imwitor 988 in dissolving LC material due to high monoglyceride content and moreover, its ability as polar oil to depress the phase inversion temperature (PIT) of the system.

\section{CONCLUSION}

There are various key elements in the oil composite that have to be optimized for successful lipid-based drug delivery systems. An oilcosurfactant ratio is one of these factors which affect the physicochemical characteristics of the resultant microemulsion systems designed for oral delivery. Oil blends of Miglyol 812 as an oil and Imwitor 988 as a cosurfactant were optimized for microemulsion systems at ratios of 1:1 in the case of Cremophor RH40 or EL, and at 2:3 in the case of Crillet 4 or Tagat 02. Furthermore, Chemical structure of surfactants and their HLB values are amongst the important factors which affect microemulsion systems. For type III lipid systems to obtain small droplet size and fast dispersion rate, hydrophilic surfactants with HLB values between 13 and 15 were found to be the best. Furthermore, hydrophilic surfactants of caster oil derivative or with oleic acid residue were found to be the most effective for microemulsion systems. Spontaneous microemulsification in type III lipid system was attributed to the "diffusion and stranding" theory whereby, diffusion of water into the oil mixture caused migration of the hydrophilic material away into the aqueous phase leading leading to nucleation oil droplets. Yet, the formation of liquid crystalline phases as intermediate phases during dilution of the oil formulation with water appears to be quintessential for the mechanistics of emulsification regardless type of lipid class system.

\section{ACKNOWLEDGMENT}

I am grateful to my supervisors Dr. Stephen Moss and Prof. Colin Pouton for their endless support, guidance and encouragement throughout this project. I am also grateful to the Department of Pharmacy and Pharmacology at Bath University for providing a good atmosphere and excellent facilities of research. I am also thankful to Capsugel for their sponsorship and to Goldschmidt (Germany), BASF Corporation, Condea Chemie (Hüls), Gattefossé and Croda who have been providing us with the excipients needed. Finally, my gratitude's go to the school of Pharmacy at Applied Science Private University for their support.

\section{AUTHORS CONTRIBUTIONS}

All the author have contributed equally

\section{CONFLICTS OF INTERESTS}

Author has none to declare

\section{REFERENCES}

1. Shah NH, Carvajal MT, Patel CI, Infeld MH, Malick AW. Selfemulsifying drug delivery system (SEDDS) with polyglycolyzed 
glycerides for improving in vitro dissolution and oral absorption of lipophilic drugs. Int J Pharm 1994;106:15-23.

2. Farah N, De Teddeo M, Larfret JP, Denis J. Self-microemulsifying drug delivery system for improving in vitro dissolution of drugs. AAPS Annual Meeting Orlando, FL; 1993.

3. Hasan MYN. Self-micro-emulsifying lipid formulations to improve the bioavailability of poorly water-soluble drugs. $\mathrm{Ph}$. D. thesis, University of Bath; 2004.

4. Hasan NM. Role of medium-chain fatty acids in the emulsification mechanistics of self-micro-emulsifying lipid formulations. Saudi Pharm 2014;22:580-90.

5. Hasan NMY, Hayajneh FM, Khaleel MA, Alharthi SA, Shahada HM, Almalki HF. Development of potential selfmicroemulsifying lipid formulation for the oral administration of curcumin. Int J Adv Pharm Biol Chem 2015;4:590-602.

6. Mohsin K. Design of lipid-based formulations for oral administration of poorly water-soluble drug fenofibrate: effect and digestion. AAPS Pharam Sci-Tech 2012;13:637-47.

7. Savla R, Browne J, Plassat V, Wasan KM, Wasan EK. Review and analysis of FDA approved drugs using lipid-based formulations. Drug Dev Ind Pharm 2017;43:1743-58.

8. Pouton CW. Lipid formulations for oral administration of drugs: non-emulsifying, self-emulsifying and "self-microemulsifying" drug delivery systems. Eur J Pharm Sci 2000;11:93-8.

9. Pouton CW. Formulation of poorly water-soluble drugs for oral administration: physicochemical and physiological issues and the lipid formulation classification system. Eur J Pharm Sci 2006;29:278-87.

10. Tung NT, Tran CS, Pham TM, Nguyen HA, Nguyen TL, Chi SC, et al. Development of solidified self-microemulsifying drug delivery systems containing l-tetrahydropalmatine: design of experiment approach and bioavailability comparison. Int J Pharm 2018;537:9-21.

11. Bhattacharya S, Mishra S, Prajapati BG. Design and development of docetaxel solid self-microemulsifying drug delivery system using principal component analysis and $\mathrm{d}$ optimal design. Asian J Pharm 2018;12:122-44.

12. Chen ZQ Liu Y, Zhao JH, Wang L, Feng NP. Improved oral bioavailability of poorly water-soluble indirubin by a supersaturatable self-microemulsifying drug delivery system. Int J Nanomed 2012;7:1115-25.

13. Pattewar S, Kasture SB, Pande VV, Patil DN, Sharma SK. Development and optimization of piroxicam-loaded solid selfmicroemulsifying drug delivery system. Indian J Pharm Sci 2018;80:350-8

14. Shah A, Thool P, Sorathiya K, Prajapati H, Dalrymple D, Serajuddin ATM. Effect of different polysorbates on the development of self-microemulsifying drug delivery systems using medium chain lipids. Drug Dev Ind Pharm 2018;44:215-23.

15. Shah AV, Desai HH, Thool P, Dalrymple D, Serajuddin ATM. Development of self-microemulsifying drug delivery system for oral delivery of poorly water-soluble nutraceuticals. Drug Dev Ind Pharm 2018;44:895-901.

16. Shukla A, Janich M, Jahn K, Krause A, Kiselev MA, Neubert RHH. Investigation of pharmaceutical Oil/water microemulsions by small-angle scattering. Pharm Res 2002;19:881-6.

17. Suman K, Chandrasekhar P, Balaji S. Approaches for the development of solid self-emulsifying drug delivery systems and dosage forms. Asian J Pharm Sci 2009;4:240-53.

18. Levy JM, Benita S. Drug release from submicronized o/w emulsion: a new in vitro kinetic evaluation model. Int J Pharm 1990;66:958-64.
19. Kommuru TR, Gurley M, Khan MA, Reddy IK. Self-emulsifying drug delivery systems (SEDDS) of coenzyme $Q_{10}$ : formulation development and bioavailability assessment. Int J Pharm 2001;212:233-46.

20. Gao ZG, Choi HG, Shin HJ, Park KM, Lim SJ, Hwang KJ, et al. Physicochemical characterization and evaluation of a microemulsion system for oral delivery of cyclosporin A. Int J Pharm 1998;161:75-86.

21. Lawrence MJ, Microemulsions as drug delivery vehicles. Curr Opin Colloid Interf Sci 1996;1:826-32.

22. Kale NJ, Allen LV. Studies on microemulsions using Brij 96 as surfactant and glycerin, ethylene glycol and propylene glycol as cosurfactants. Int J Pharm 1989;57:87-93.

23. Eccleston GM. Microemulsions. Edited by Swarbrick S, Boylan JC. Encyclopedia of pharmaceutical technology. Marcel Dekker, New York; 1992. p. 375-421.

24. Kawakami K, Yoshikawa T, Moroto Y, Kanaoka E, Takahashi K Nishihara $\mathrm{Y}$, et al. Microemulsion formulation for enhanced absorption of poorly soluble drugs: I. prescription design. J Controlled Release 2002;81:65-74.

25. Kawakami K, Yoshikawa T, Hayashi T, Nishihara Y, Masuda K. Microemulsion formulation for enhanced absorption of poorly soluble drugs: II. In vivo study. J Controlled Release 2002;81:75-82.

26. Lu JR, Su TJ, Lawrence MJ, Barlow DJ, Warisnoichareon W, Zuberi T. The and composition of ethyl hexadeconate layers spread on aqueous solution of hexaethylene glycol monododecyl ether. J Phys Chem B 1999;103:4638-48.

27. Kunieda H, Horii M, Koyama M, Sakamoto K. Solubilisation of polar oils in surfactant self-organized structures. J Colloid Intref Sci 2001;236:78-84.

28. Chen Y, Li G, Wu X, Chen Z, Hang J, Qin B, et al. Selfmicroemulsifying drug delivery system (SMEDDS) of vinpocetine: formulation development and in vivo assessment. Biol Pharm Bull 2008;31:118-25.

29. Hasan NMY, SH Moss SH, Pouton CW. The choice of non-ionic surfactant in self-micro-emulsifying lipid formulations for the oral delivery of poorly water-soluble compounds. J Pharm Pharmacol 2005;57:S53.

30. Wakerly MG. Self-emulsifying drug delivery systems based on nonionic surfactant-oil mixtures. Ph. D. Thesis, University of Bath; 1989.

31. Pouton CW. A study of self-emulsifying oil/surfactant mixtures. $\mathrm{PhD}$ thesis, University of London; 1982.

32. Rang MJ, Miller CA. Spontaneous emulsification of oil droplets containing surfactants and medium-chain alcohols. Prog Colloid Polym Sci 1998;109:101-7.

33. Rang MJ, Miller CA. Spontaneous emulsification of oils containing hydrocarbon, Nonionic surfactant, and oleyl alcohol. J Colloid Interface Sci 1999;209:179-92.

34. Lin TJ, Kurihara H, Ohta H. Prediction of optimum $\mathrm{o} / \mathrm{w}$ emulsification via solubilization measurements. J Soc Cosmet Chem 1977;28:457-79.

35. Pouton CW. Formulation of self-emulsifying drug delivery systems. Adv Drug Delivery Rev 1997;25:47-58.

36. Pouton CW, Wakerly MG, Meakin BJ. Self-emulsifying systems for oral delivery of drugs. Proc Int Symp Controlled Release Bioact Mater 1987;14:113-4.

37. Wakerly MG, Pouton CW, Meakin BJ, Morton FS. Selfemulsification of vegetable oil-nonionic surfactant mixtures: a proposed mechanism of action. ACS Symp Ser 1986; 311:242-55. 